\title{
STRATEGI PENGEMBANGAN PRODUK BUBUK KEDELAI DENGAN ANALISA SWOT PADA CV. MAKARTI POMOSDA
}

\author{
Marta Monika \\ Program Studi Teknik Industri, STT POMOSDA Nganjuk
}

Agustin Sukarsono

Program Studi Teknik Industri, STT POMOSDA Nganjuk, agustystt@gmail.com

Sumarsono

Program Studi Teknik Industri, Teknik, Universitas Hasyim Asy’ari, $\underline{\text { sonsumarsono13@ gmail.com }}$

\begin{abstract}
Abstrak
Dalam sebuah usaha pengembangan produk haruslah sesuai dengan tujuan yang diinginkan oleh perusahaan. Sehingga konsumen akan selalu terpenuhi keinginannya dengan bentuk dan model produk baru serta perubahan-perubahan seperti ciri khusus produk, mutu produk, tipe produk, dan ukuran produk untuk kebutuhan dan keinginan pelanggan.Analisis SWOT adalah salah satu metode dalam mencari solusi permasalahan perusahaan yang ada baik internal maupun eksternal. Analisis ini digunakan untuk memaksimalkan kekuatan (Strengths) dan peluang (Opportunities), dan meminimalkan kelemahan (Weaknesses) dan ancaman (Threats). Proses pengambilan keputusan harus sesuai dengan tujun yang ingin dicapai oleh perusahaan..Dengan Memakai matriks IFAS dan EFAS dapat memetakan strategi untuk pengembangan produk Kedelai Marasake sesuai dengan Visi Misi CV. Makarti untuk meningkatkan daya saing bubuk kedelai marasake dalam lingkup luas tidak hanya jamaah saja, melainkan juga di pasar global.
\end{abstract}

Kata Kunci : SWOT, Matriks IFAS EFAS, Makarti.

Abstract

In a product development business must be in accordance with the objectives desired by the company. So that consumers will always be fulfilled by their desire with new product forms and models and changes such as product specific characteristics, product quality, product type, and product size for customer needs and desires. SWOT analysis is one method in finding solutions to existing company problems. internal or external. This analysis is used to maximize Strengths and Opportunities, and minimize Weaknesses and threats. The decision-making process must be in accordance with the goals that the company wants to achieve ... Using matrix IFAS and EFAS can map out strategies for the development of Marasake Soybean products in accordance with the Vision Mission CV. Makarti to increase the competitiveness of marasake soybean powder in a wide scope not only worshipers, but also in the global market.

Keywords: SWOT, IFAS EFAS Matrix, Makarti.

\section{PENDAHULUAN}

Persaingan dalam sebuah industri sudah wajar terjadi, hal ini dalalm dunia pendidikan sangat diharapkan perananannya untuk mendukung dengan tindakan karya nyata dalam membangun bangsa dan negara. Dalam dunia kerja dituntut untuk mendapatkan sumber daya yang mempunyai tingkat professionalitas yag tinggi. Karena semangat dan kinerja yang professional sangat dibutuhkan untuk pengembangan produk dan usaha untuk mencari profit.

Siklus hidup perusahaan ditandai dengan indikator yaitu sebuah kepuasan konsumen. Konsumen yang loyal pasti membeli produk dan menggunakan kembali jasa pada saat kebutuhan yang sama muncul kembali dikemudian hari. Menurut Rangkuti (2006), “Kepuasan pelanggan merupakan respon pelanggan terhadap ketidaksesuaian antara tingkat kepentingan sebelumnya dan kinerja aktual yang dirasakannya setelah pemakaian". Untuk itu perusahaan harus bisa menghasilkan dan menyampaikan barang atau jasa kepada konsumen dengan memberikan pelayanan terbaiknya.

Parasuraman (2005), berpendapat bahwa "Tersedianya fasilitas adalah secara fisik, perlengkapan, sarana komunikasi dan lainya harus ada dalam proses jasa". Fasilitas merupakan salah satu pertimbangan konsumen dalam penentuan pilihan.

Menurut Hary (dalam Tjiptono, 2006), "Kualitas pelayanan merupakan suatu proses atau aktivitas yang dilakukan oleh perusahaan yang dapat dirasakan secara langsung hasilnya, 
yang pada akhirnya dapat memenuhi harapan pelanggan". Kualitas diharapkan dapat memberikan sesuatu yang lebih kepada pelanggan untuk menjalin ikatan hubungan yang kuat dengan perusahaan.

\section{PEMBAHASAN DAN PENGOLAHAN DATA}

4.4.3 Demografi pegawai yang diberdayakan di Makarti

Dari hasil pengamatan dan penelitian data di kantor makarti, ada 12 pegawai yang diberdayakan yaitu :

1. Jenis Kelamin

Tabel 4.5 jumlah pegawai marketing dan administrasi Marasake

\begin{tabular}{|c|c|c|c|}
\hline No & Nama & Jumlah & Presentase \\
\hline 1 & Laki-laki & 5 Orang & $50 \%$ \\
\hline 2 & Perempuan & 5 Orang & $50 \%$ \\
\hline & Jumlah & 10 Orang & $100 \%$ \\
\hline
\end{tabular}

2. Tingkat Usia

Table 4.6 Usia pegawai

\begin{tabular}{lccc}
\hline No & $\begin{array}{c}\text { Usia } \\
\text { (umur) }\end{array}$ & Jumlah & Presentase \\
\hline $\mathbf{1}$ & $20-25$ & 3 Orang & $30 \%$ \\
\hline $\mathbf{2}$ & $26-31$ & 4 Orang & $40 \%$ \\
\hline $\mathbf{7}$ & $32-37$ & 3 Orang & $30 \%$ \\
\hline & Jumlah & 10 Orang & $\mathbf{1 0 0} \%$ \\
\hline & Sumber & : Data diolah 2017
\end{tabular}

3. Tingkat pemasaran

Table 4.7 pemasaran

\begin{tabular}{lccc}
\hline No & Tahun & Jumlah & Presentase \\
\hline $\mathbf{1}$ & 2012 & 2 Orang & $7 \%$ \\
\hline $\mathbf{2}$ & 2013 & 6 Orang & $21 \%$ \\
\hline $\mathbf{3}$ & 2014 & 3 Orang & $11 \%$ \\
\hline $\mathbf{5}$ & 2015 & 9 Orang & $33 \%$ \\
\hline & 2016 & 2 Orang & $7 \%$ \\
\hline
\end{tabular}

Sumber: Data Primer 20

4. Tingkat penjualan

Table 4.8 penjualan per tahun

\begin{tabular}{lcccc}
\hline No. & Tahun & Tahun & Tahun & Tahun \\
& $\mathbf{2 0 1 2}$ & $\mathbf{2 0 1 3}$ & $\mathbf{2 0 1 4}$ & $\mathbf{2 0 1 5}$ \\
\hline Marasake & 8732 & 2795 & 2293 & 1411 \\
Kedelai & pcs & pcs & pcs & pcs \\
\hline Marasake & 1796 & 1138 & 899 & 672 \\
Kacang & pcs & pcs & pcs & pcs \\
Hijau & & & & \\
\hline Jumlah & 10.528 & 3.933 & 3192 & 2083 \\
& pcs & pcs & pcs & pcs \\
\hline
\end{tabular}

Sumber : Data diolah 2017

4.4.4 Analisa SWOT awal mengenai produk susu bubuk kedelai merk Marasake

1. Produk susu bubuk

Kedelai merk marasake.

\section{Kekuatan (S) \\ 1. Produksi kedelai kaya manfaat \\ 2. Budidaya kedelai \\ 3. Kedelai mudah tumbuh}

Kelemahan (W)

1. banyak kompetitor

2. petani kedelai jarang

3. evaluasi

4. minimnya pengetahuan petani kedelai tentang pola tanam organik

Peluang (O)

1. Menciptakan benih unggul

2. permintaan kedelai yang tinggi

3. kepedulian dari SDM yang kuat

4. sisa olahan dpat dipergunakan sebagai pakan ternak

Strategi SO.

Strategi SO adalah strategi penggunaan kekuatan untuk memanfaatkan peluang. Rumusan Strategi SO adalah sebagai berikut:

1. Membentuk dan mengembangkan usaha pembibitan kedelai unggul

2. Meningkatkan penyuluhan mengenai nilai gizi susu kedelai marasake dan cara bertanam yang baik.

3. Memperluas pangsa pasar kedelai marasake dengan meningkatkan jaringan ke berbagai daerah, sehingga perlu meningkatkan koordinasi dengan instansi terkait home industry.

Strategi WO.

Strategi WO adalah strategi meminimalkan kelemahan untuk memanfaatkan peluang

1. Meningkatkan sosialisasi terhadap nilai gizi kedelai marasake dalam upaya memanfaatkan kedelai dengan berbagai olahan produktif serta promosi, dan perkembangan pertanian organik.

2. Menumbuhkembangkan kesadaran prinsip kebersamaan untuk mengelola administrasi usaha kedelai marasake.

Strategi ST.

Strategi ST adalah strategi yang difokuskan pada upaya meminimalkan kelemahan untuk menghindari ancaman. Strategi ST dirumuskan sebagai berikut: 
1. Mengembangkan pusat kesehatan tanaman dalam rangka pencegahan hama penyakit.

Marasake KACANG HIJAU

\begin{aligned} & \hline Kekuatan $(\mathrm{S}) \\ &$ 1. \\ & mudah \\ & dikembangbiakk \\ & an \\ & 2. Perawatan \\ & mudah \\ & 3. sudah menjadi \\ & kebiasaan para \\ & petani untuk \\ & bertanam \\ & 4. bisa digunakan \\ & untuk pakan \\ & hewan ternak \end{aligned}

Peluang (O)

1. Permintaan pasar yang tinggi

2. perkembangan inovasi

\section{Kelemahan (W) \\ 1. Sebagian \\ besar sistem pemeliharaan masih secara tradisional \\ 2. SDM petani yang rendah \\ 3. keterbatasan bibit yang unggul \\ 4. kurangnya perhatian dari pemerintah} Hambatan (T) 1. Penyakit hama.

2. persaingan usaha

3. harga yang

3. harga t yang tinggi

\section{Strategi SW}

1. Peningkatan SDM terkait budidaya kacang hijau.

2. terobosan pupuk organic yg sdh diolah dan teruji

3. melakukan kerjasama pasar dengan konsumen langsung

4. menciptakan pengembangan olahan kacang hijau.

4.5. Tahap Masukan (Input Stage)

Tahap masukan terdiri dari matriks IFE (Internal Factor Evaluation) dan EFE (External Factor Evaluation). Tahap ini merupakan tahap awal dalam merumuskan strategi setelah mengidentifikasi faktor-faktor eksternal dan internal.

\subsubsection{Matriks IFE (Internal Factor Evaluation)}

Setelah melakukan identifikasi terhadap faktorfaktor internal perusahaan, selanjutnya dibuat matriks IFE yang berisi kekuatan dan kelemahan perusahaan. Data diolah dengan membandingkan tingkat kepentingan satu sama lain, sehingga diketahui nilai faktor yang berpengaruh terhadap perusahaan. Setelah itu nilai total faktor pada masing-masing variabel dibagi dengan nilai total keseluruhan faktor yang diidentifikasi sehingga dihasilkan besar bobot yang diperlukan.

Berdasarkan identifikasi terhadap faktor-faktor strategis internal, diperoleh kekuatan (stregths) dan kelemahan (weaknesses) yang dimiliki perusahaan. Faktorfaktor strategis internal didapat dari hasil wawancara dan observasi. Pembobotan dilakukan dengan menggunakan matriks pasangan berganda (paired comparison matrix) untuk mendapatkan bobot dari masing-masing variabel internal.

Setelah didapatkan hasil identifikasi kekuatan dan kelemahan sebagai faktor internal strategis, langkah selanjutnya memberikan bobot dan peringkat seperti ditunjukkan pada Tabel 4.9

Tabel 4.9. Matriks IFE (Internal Factor

$$
\text { Evaluation) }
$$

\begin{tabular}{llll}
\hline Faktor-faktor & Bobot & $\begin{array}{l}\text { Pering } \\
\text { kat }\end{array}$ & $\begin{array}{l}\text { Nilai } \\
\text { Tertimbang }\end{array}$ \\
\hline Strategis Internal & & Ramb
\end{tabular}

Kekuatan (Strengths)

A. Hubungan ketua $0.13 \quad 2 \quad 0.260$ dengan kelompok

tani

B. Produk yang

berkualitas

\begin{tabular}{llll} 
& 0.09 & 3 & 0.270 \\
\hline C. & Pelayanan & &
\end{tabular}

C. Pelayanan

konsumen yang

sudah baik

$\begin{array}{lllll} & & 0.12 & 2 & 0.253 \\ \text { D. Sudah memiliki } & 0.13 & 2 & 0.260\end{array}$

kemasan

Kelemahan (Weaknesses)

\begin{tabular}{|c|c|c|c|}
\hline $\begin{array}{l}\text { E. Kualitas SDM } \\
\text { yang masih rendah }\end{array}$ & 0.08 & 2 & 0.166 \\
\hline $\begin{array}{l}\text { F. Belum dapat } \\
\text { memanfaatkan } \\
\text { peluang }\end{array}$ & 0.04 & 2 & 0.083 \\
\hline $\begin{array}{l}\text { G. Pengarsipan data } \\
\text { yang belum rapi }\end{array}$ & 0.08 & 2 & 0.173 \\
\hline $\begin{array}{lr}\text { H. } & \text { Teknologi } \\
\text { produksi } & \text { yang } \\
\text { digunakan } & \text { masih } \\
\text { sederhana } & \\
\end{array}$ & 0.06 & & 0.126 \\
\hline
\end{tabular}

Total $\quad 1 \quad 1,591$

\section{KESIMPULAN}

Dari hasil penelitian yang telah dilakukan maka dapat diperoleh kesimpulan sebagai berikut:

1.Strategi SO :

a. Membentuk dan mengembangkan budidaya usaha pembibitan kedelai unggul

b. Meningkatkan penyuluhan mengenai nilai gizi kedelai dan cara budidaya kedelai yang baik

2. Strategi WO.

a. Meningkatkan sosialisasi terhadap nilai gizi kedelai dalam upaya memanfaatkan kedelai yang tidak produktif serta promosi, dan budidaya kedelai. 
b. Menumbuh kembangkan kesadaran masyarakat/petani kedelai dengan prinsip kebersamaan untuk membentuk administrasi keuangan agar mempermudah pencatatan pendapatan dan pengeluaran dalam usaha pengembangan bubuk instan kedelai marasake

3. Strategi ST.

Mengembangkan pusat pengembangan bibit dalam rangka pencegahan hama penyakit.

4. Strategi SW.

a. Mengingat kebutuhan terus-menerus meskipun musiman agar dibuatkan tempat penyimpanan untuk terjaganya siklus produksi

b. Peningkatan standart mutu untuk perkuatan marketing

\section{DAFTAR PUSTAKA}

Abraheem Shlash Mohammad, Shireen Yaseen Mohammad Alhamadani. (2011) Service Quality Perspective and Customer Satisfaction in Commercial Banks Working in Jordan, Petra University

Andaleeb, S.S. dan Conway, C., 2006, Customer Satisfaction in The Restaurant Industry: an Examination of The TransactionSpecific Model, Journal of Services Marketing

Assauri,Sofjan.2009.Manajemen Pemasaran Konsep Dasar dan Strategi,edisi pertama.Jakarta:Rajagrafindo

Amstrong, Gary and Kotler, Philip, 2008, Prinsip - Prinsip Pemasaran, Edisi 12, Erlangga: Jakarta

digilib.uinsby.ac.id/9289/6/bab\%202.pdfoleh J Jarwanto - 2011

Djaslim Saladin, 2007, Manajemen Pemasaran, Bandung; Linda Karya.

Indriyo Gitosudarmo, 2008, Manajemen Pemasaran, edisi pertama, cetakan keempat, Penerbit : $\quad$ BPFE Yogyakarta

Griffin, J, 2005, Customer Loyalty, Lexington Books, Newyork.

Kotler,philp and Gary Armstrong. 2012 Prinsip-prinsip Pemasaran. Edisi ke 13 Jilid 1. Jakarta Erlangga

Kotler, Phillip \& Kevin L. Keller. 2006. Marketing Management, 12th Edition. New Jersey: Pearson International Edition 